\title{
Mupirocin Pemphigus-Like Drug Reaction in a Dog
}

\author{
Tiago Cunha Ferreira, Rodrigo Fonseca de Medeiros Guedes, \\ Belise Maria Oliveira Bezerra \& Diana Célia Sousa Nunes-Pinheiro
}

Background: Pharmacodermia is defined as adverse reaction in skin, mucosa and appendages, which generates morphofunctional alterations in cutaneous barrier, inducing autoimmune diseases, such as pemphigus foliaceous, which is known as the most common autoimmune skin disease in dogs. This disease involves autoantibodies against desmoglein and desmocolin molecules, being induced by the use of certain drugs. Mupirocin (pseudomonic acid A) is a broad-spectrum antibiotic with bacteriostatic activity, being effective against Gram-positive pathogens and used to control superficial bacterial folliculitis. Based on that, the aim of this study was to report a pemphigus-like lesions after topical use of mupirocin in dog.

Case: An 1-year-old, uncastrated male, Poodle dog, weighing $13.8 \mathrm{~kg}$ was treated in a private clinic in Fortaleza. The main complaint was related to pruritus in abdominal and inguinal region, in addition of legs licking. Dermatological examination revealed melanic crusts, epidermal collars and diffuse pustules in inguinal, abdominal, perianal and thoraco-lumbar regions. The therapy was based on topical use of Mupirocin in form of $0.2 \%$ aquous spray. After drug administration, the animal presented urticaria, diffuse epidermal collars, papulo-crusted and pustular lesions, which were more evident in abdominal and inguinal region. Nasal erythema, binocular blepharitis, apathy and fever were also observed. Cytological examination and bacterial culture were performed, revealing inflammatory and acantholytic cells and no bacterial growth. Biopsy procedure revealed subcorneal pustule with presence of epithelial acantholytic cells and neutrophils, compatible with canine pemphigus foliaceous. The topical treatment of ocular lesions with $0.1 \%$ Tacrolimus associated with systemic treatment with high dose of prednisolone $\left(1.2 \mathrm{mg} \mathrm{kg}^{-1}\right)$. The patient improved the dermatological clinical signs, however, some side effects have already become evident, such as the presence of telangiectasia, polyuria, polyphagia and polydipsia. Heterodox therapy based on the use of azathioprine $\left(2 \mathrm{mg} \mathrm{kg}^{-1}\right)$ was chosen in order to reduce corticoid dose. After 3 days of therapy, blood material was collected for hepatic evaluation, detecting hepatotoxicity. From the results, azathioprine therapy was suspended, and only high-dose corticosteroid therapy $\left(1.5 \mathrm{mg} \mathrm{kg}^{-1}\right)$ was maintained. The patient presented a considerable improvement in the lesion after 10 days of treatment.

Discussion: There have been reports that pharmacodermic reactions may be associated with the development of autoimmune diseases, such as pemphigus foliaceus and vulgaris. In some cases, the lesions regress after drug discontination. In others, the medication acts as a triggering factor, activating the genetic predisposition of patient, which develops the pathology even after therapy interruption. The drug related pemphigus-foliaceous is a well-recognized disease in humans, however this disease is limited to sporadic cases in dogs. The therapy was based in use of a high dose of prednisolone, which caused some side effects. Therefore, a heterodox therapy was chosen in order to reduce the corticoid dosage. At the first hemato-biochemical evaluation, the patient already presented significant alterations, being requested to suspend the prescribed treatment, although the owners already reported improvement of the dermatological lesions. Due to this, a higher dose of prednisolone was chosen, obtaining the best response among the therapies used since the beginning of the treatment. After clinical improvement, the gradual reduction of steroidal therapy was started in order to avoid side effects related to suppression of the hypothalamic-pituitary-adrenal axis. This report provides evidences of Mupirocin as a potential triggering factor of pemphigus-like lesions in dogs.

Keywords: cutaneous adverse drug reaction, drug allergy, canine autoimmune disease. 


\section{INTRODUCTION}

Pharmacodermic reactions are defined as adverse manifestations in skin, mucosa and appendages due to topical or systemic drugs, which may cause structural or functional alterations in skin, reflecting on localized or generalized lesions $[6,13,22]$. These reactions can also trigger the development of autoimmune diseases, such as pemphigus foliaceous (PF), in predisposed individuals, which can progress even after drug discontinuation [10].

$\mathrm{PF}$ is known as the most common autoimmune skin disease in dogs, involving naturally or induced autoantibodies production against desmoglein and desmocolin molecules $[1,3]$. Iatrogenic PF is subdivided in drug-induced, which drug discontinuance leads to disease regression, or drug-triggered, where the drug stimulates the disease natural development and progression $[10,24]$. PF caused by drugs is well described in humans, associated to different drugs, such as angiotensin converting enzymes inhibitors and antibiotics [21].

Mupirocin (pseudomonic acid A) is a broadspectrum antibiotic with bacteriostatic activity, being effective against Gram-positive pathogens, specially staphylococci and streptococci [7]. In dogs, it is used to control superficial bacterial folliculitis [8], showing a low prevalence of resistance [16].

Considering the lack of reports about drugrelated PF in dogs [9], the objective of the present study is to describe the occurrence of pemphigus-like lesions in consequence of a pharmacodermic reaction following a topical application of mupirocin.

\section{CASE}

An 1-year-old, uncastrated male, Poodle dog, weighing $13.8 \mathrm{~kg}$ was treated in a private clinic in Fortaleza. The main complaint was related to pruritus in abdominal and inguinal region, in addition of legs licking. At the general clinical examination, the following observations were made: active patient, hydrated, temperature of $38.7^{\circ} \mathrm{C}$ and non-palpable lymph nodes. No ectoparasites were seen. Dermatological examination revealed meliceric crusts, epidermal collars and diffuse pustules in the inguinal, abdominal, perianal and thoraco-lumbar regions (Figure 1A). The legs were erythematous, as were the ears. Areas of alopecia were not visualized. The hairs were clean and the skin slightly oily. Therefore, through the information collected in anamnesis and clinical examination, the use of topical therapy with mupirocin $\left(\text { Bactroban }^{\circledR}\right)^{1}$ in form of $0.2 \%$ aqueous spray, BID, for 15 days.

After initiation of treatment, the patient presented lesion worsening, such as increased quantity and size of epidermal pustules and collars, besides the appearance of urticaria and papular-crusted lesions in diffuse areas of the body, being more evident in abdominal and inguinal regions (Figure 1B).

On the occasion, cytological examination and bacterial culture were performed with material from the secretion of meliceric crusts and epidermal collars. Inflammatory cells were characterized, mostly, by intact and rare degenerated neutrophils, interspersed with acantholytic cells (Figure 2A). Regarding the bacterial culture, there was no growth of any bacteria from the collected sample. From the data, it was suspected of pharmacodermia related to mupirocin, being requested the drug suspension and added immunosuppressive drugs to treatment protocol. After the exchange of the previously adopted therapy, the patient improved the clinical picture, showing remission of the lesions and pruritus (Figure 1C/1D).

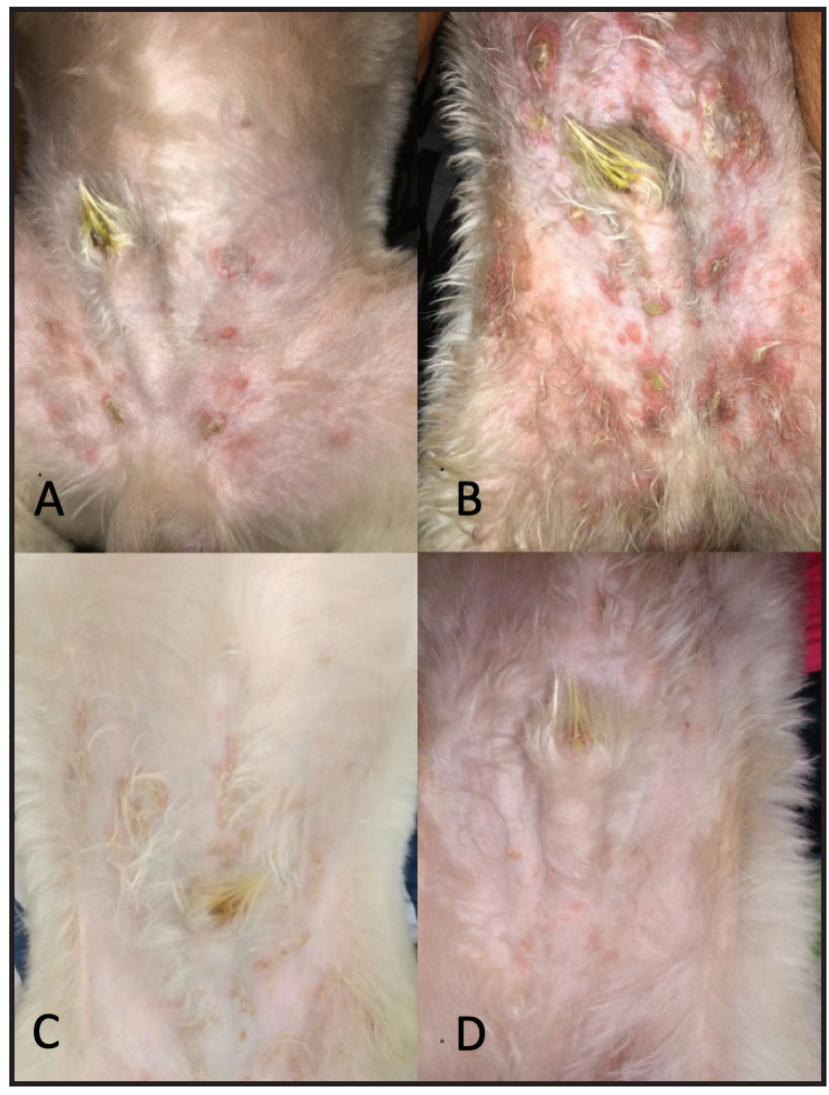

Figure 1. Aspects of skin lesions before (A) and 4 days after (B) topical use of mupirocin. Treatment after cutaneous mupirocin drug reaction - 07 days (C) and 15 days (D). [Source: T.C. Ferreira]. 


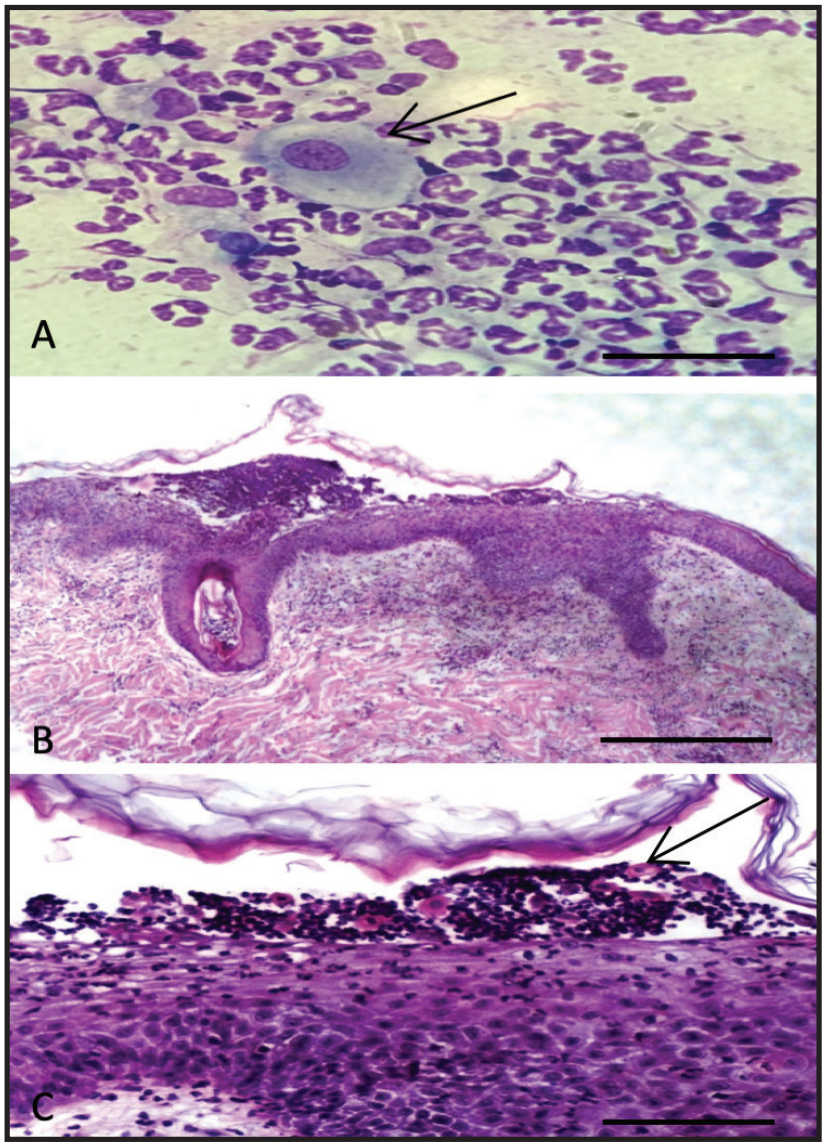

Figure 2. Cytological evaluation (A) presents inflammatory infiltrate caractherized by neutrophils, macrophages and acantholytic keratinocytes (arrow). Original magnification: 1000x. [Scale bar $=50 \mu \mathrm{m}$ ]. Skin biopsy revealed subcorneal pustule, with acantholytic epithelial cells interspersed by a large number of intact neutrophils. H\&E, Original magnification: 100x (B) and 400x (C). [Scale bar $=50 \mu \mathrm{m}$ ]. [Source: T.C. Ferreira].

However, with the gradual reduction of drug dosage, there were reappearance of diffuse pustules and crustal lesions in chest, cervical, thoracic and lumbar regions. In addition to these lesions, the appearance of nasal erythema (Figure 3A), blepharitis (Figure 3B), apathy and fever $\left(39.9^{\circ} \mathrm{C}\right)$ were observed.

With the appearance of such lesions, it was suspected that the patient was developing drug-triggered pemphigus foliaceous. The topical treatment of ocular lesions with $0.1 \%$ tacrolimus (Protopic $\left.{ }^{\circledR}\right)^{2}$ associated with systemic treatment with $1.2 \mathrm{mg} \mathrm{kg}^{-1}$, SID, of prednisolone $\left(\text { Alcort }^{\circledast}\right)^{3}$. The patient improved the dermatological clinical picture, however, some side effects have already become evident, such as the presence of telangiectasia, polyuria, polyphagia and polydipsia. Heterodox therapy based on the use of $2 \mathrm{mg} \mathrm{kg}^{-1}$, SID, of azathioprine (Imuran $\left.{ }^{\circledR}\right)^{4}$ was chosen in order to reduce corticoid dose. After 3 days of therapy, blood sample was collected for hepatic evaluation, detecting

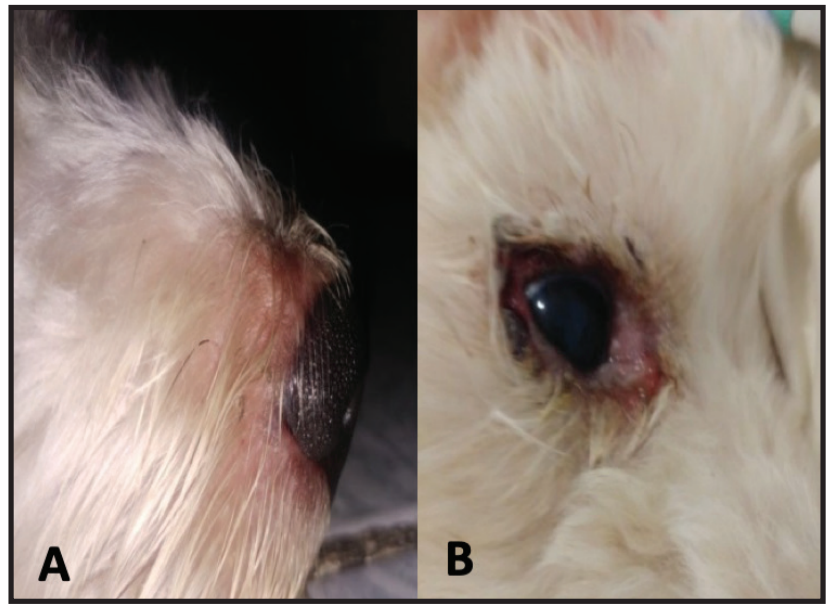

Figure 3. Skin lesions in nasal planum (A) and eye (B). [Source: T.C. Ferreira].

hepatotoxicity. The hemato-biochemical parameters are represented in Table 1.

From the results, azathioprine therapy was suspended, and a dose of $1.5 \mathrm{mg} \mathrm{kg}^{-1}$, SID, of prednisolone was maintained. The patient presented a considerable improvement in the lesion after 10 days of treatment, with remission of lesions almost all over the body and reduction of size, frequency and amount of pustules. The side effects observed with the use of the medication in high dose involved the same previously mentioned, besides the presence of pendular abdomen and weakness in respiratory muscles, being reflected in a clinical picture of mild dyspnea.

After a new corticoid dose reduction, it was possible to perform cutaneous biopsy of an intact pustule, and this material was submitted to histopathological examination. The report revealed the presence of subcorneal pustule, with presence of acantholytic epithelial cells interspersed by a large number of intact neutrophils (Figure 2B). The microscopic aspect of the lesion, along with the clinical findings and other complementary tests, revealed a clinical picture compatible with Canine Pemphigus Foliaceus. The patient continues to follow up until the present moment where it is perceived that, with low doses of immunosuppressive therapy, there is recurrence of the lesions.

\section{DISCUSSION}

The clinical case described demonstrates the occurrence of pemphigus foliaceous due to pharmacodermic reaction after topical administration of $\mathrm{Mu}$ pirocin. This disease is known as the most common auto-immune skin disease in dogs and involves the 
Table 1. Hemato-biochemical parameters in a dog with drug-triggered pemphigus foliaceous. T0 represents the hemato-biochemical parameters before treatment with corticosteroids and azathioprine. T1 represents the parameters after azathioprine and low dose of corticosteroids. T2 represents the parameters after azathioprine removal and high dose of corticosteroids.

\begin{tabular}{ccccc}
\hline \multirow{2}{*}{ Parameter } & \multicolumn{5}{c}{ Timeline } \\
\cline { 2 - 5 } & T0 & T1 & T2 & Min-Max* \\
\hline RBC $\left(\times 10^{6} / \mu \mathrm{L}\right)$ & 5.5 & 5.9 & - & $5.5-8.5$ \\
Hematocrit $(\%)$ & 37.3 & 39.3 & - & $37-55$ \\
WBC $\left(\mathrm{x} 10^{3} / \mu \mathrm{L}\right)$ & 10.4 & 15.0 & - & $6.0-17.0$ \\
Neutrophils $(\mathrm{U} / \mathrm{L})$ & 7.3 & 12.9 & - & $3.0-11.5$ \\
Total Proteins $(\mathrm{g} / \mathrm{dL})$ & 10.0 & 8.4 & - & $6.0-8.0$ \\
ALT/GPT $(\mathrm{U} / \mathrm{L})$ & 38.0 & 277.6 & 67.0 & $10.0-88.0$ \\
ALP $(\mathrm{U} / \mathrm{L})$ & 32.0 & 981.0 & 174.0 & $20.0-150.0$ \\
BUN $(\mathrm{mg} / \mathrm{dL})$ & - & 104.7 & 65.3 & $21.0-60.0$
\end{tabular}

*Reference [11].

synthesis of antikeratinocyte autoantibodies $[3,14,15]$. The clinical suspicion was based on the clinical-cytological patterns coincident with the administration of the medication, where the dermatological lesions, such as urticaria and pruritus, were compatible with those previously described [19].

There have been reports that pharmacodermic reactions may be associated with the development of autoimmune diseases, such as pemphigus foliaceus and vulgaris. In some cases, the lesions regress after drug discontinuation. In others, the medication acts as a triggering factor, activating the genetic predisposition of patient, which develops the pathology even after therapy interruption $[5,18]$. The drug related PF is a well-recognized disease in humans [24], however this disease is limited to sporadic cases in dogs [14,20,23]. At the authors knowledge, this is the first report of Mupirocin as a PF triggering factor.

For diagnostic help regarding pharmacodermia, a clinic algorithm was used. This method is based on a questionnaire which, according to the answers, it generates a final score, in order to try to establish a causal relationship between the use of the drug and the clinical signs presented by the pacient [12]. The ratio of the 10 questions analyzed provided a score of 07 , which characterizes the drug administration as a probable cause of lesions. In order to acquire a larger score, which would define the cause of pharmacodermic reaction, the drug should be readministered. However, such procedure has not been performed aiming at the health integrity of patient.
Cytological evaluation and bacterial culture of the material obtained from the secretion of meliceric crusts and epidermal collars were performed. The cytology content (Figure 2A) was similar to that reported in patients with a pemphigus-like reaction to a drug $[2,20]$. Regarding bacterial culture, such test was requested for differential diagnosis of pyoderma. However, there was no bacterial growth, reinforcing the hypothesis of Mupirocin as causal agent of pemphigus-like lesions.

In pemphigus foliaceus, acantholysis occurs in superficial skin layers, culminating with vesico-bullous lesions that can be easily broken [4]. Such fragility present in pustules delays the diagnostic process due to absence of intact blisters that allow the correct histopathological evaluation, which would justify the late accomplishment of such complementary test. Inside the pustules it is possible to verify the presence of acantholytic cells, surrounded by neutrophils (Figure $2 \mathrm{~B} / 2 \mathrm{C}$ ). This data may indicate the cell migration from dermis to epidermis induced by chemotactic molecules from complement activation, culminating with tissue damage [17]. In addition, the damage that leads to acantholytic cells formation may also be originated from complement activation and antigen-antibody interaction over keratinocytes [3].

The adopted treatment during the clinical picture of pharmacodermia was based on the use of immunomodulatory drugs administered orally and topically. After 07 days of treatment, associated with the suspension of Mupirocin, the skin already presented clinical improvement (Figure 1C). Although skin lesions regressed early in treatment, new lesions began to appear 
together with systemic signs such as fever and apathy. Such signals were only controlled through high doses of corticosteroids. The side effects associated with the continuous use of this pharmacological group involve tegumentary and systemic alterations [10]. Among them, the patient presented cutaneous thinning, telangectasia, polyuria, polydipsia, polyphagia and weight gain.

The use of heterodox therapies in treatment of autoimmune diseases aims at the reduction of corticosteroid doses and consequent control of adverse effects [10]. Among the alternative drugs, azathioprine was used, but it was suspended due to hepatotoxicity, so a high dose of corticosteroids was chosen. The patient followed the therapy for 10 days, with excellent posttreatment results. The side effects developed were previously mentioned, but the patient has also presented frequent dyspnea due to respiratory muscle weakness.

After clinical improvement, the gradual reduction of steroidal therapy was started in order to avoid side effects related to suppression of the hypothalamic-pituitary-adrenal axis. This immunemediated disease remission was not achieved until the present moment, being possible to notice the recurrence of cutaneous lesions, although of reduced intensity, when the corticosteroid dose is reduced.

This report provides further evidences that mupirocin can cause adverse drug reaction as well as trigger the development of pemphigus-like lesions in dogs. This case also reinforces the need to understand the mechanism of topical drug-triggered $\mathrm{PF}$ in order to ensure appropriate diagnosis and treatment.

\section{MANUFACTURERS \\ ${ }^{1}$ GlaxoSmithKline Brasil Ltda. Rio de Janeiro, RJ, Brazil. \\ ${ }^{2}$ Astellas Farma Brasil Importação e Distribuição de Medicamentos Ltda. São Paulo, SP, Brazil. \\ ${ }^{3}$ Cepav Pharma Ltda. São Paulo, SP, Brazil. \\ ${ }^{4}$ Aspen Pharma Indústria Farmacêutica Ltda. Serra, ES, Brazil.}

Declaration of interest. The authors declare no conflicts of interest. The authors alone are responsible for the content and writing of the paper.

\section{REFERENCES}

1 Bizikova P., Dean G.A., Hashimoto T. \& Olivry T. 2012. Cloning and establishment of canine desmocollin-1 as a major autoantigen in canine pemphigus foliaceous. Veterinary Immunology and Immunopathology. 149(3-4): 197-207.

2 Bizikova P., Moriello K.A., Linder K.E. \& Sauber L. 2015. Dinotefuran/pyriproxyfen/permethrin pemphigus-like drug reaction in three dogs. Veterinary Dermatology. 26(3): 206-208.

3 Bizikova P., Olivry T., Mamo L.B. \& Dunston S.M. 2014. Serum autoantibody profiles of IgA, IgE and IgM in canine pemphigus foliaceus. Veterinary Dermatology. 25(5): 471-e75.

4 Balda A.C., Ikeda M.O., Larsson-Junior C.E., Michalany N.S. \& Larsson C.E. 2008. Pênfigo foliáceo canino: estudo retrospectivo de 43 casos clínicos e terapia (2000-2005). Pesquisa Veterinária Brasileira. 28(8): 387-392.

5 Brenner S., Wolf R. \& Ruocco V. 1993. Drug-induced pemphigus I. A survey. Clinical Dermatology. 11(4): 501-505.

6 Edwards I.R. \& Aronson J.K. 2000. Adverse drug reactions: definitions, diagnosis, and management. Lancet. 356(9237): 1255-1259.

7 Fuchs P.C., Jones R.N. \& Barry A.L. 1990. Interpretive criteria for disk diffusion susceptibility testing of mupirocin, a topical antibiotic. Journal of Clinical Microbiology. 28(3): 608-609.

8 Hillier A., Lloyd D.H., Scott-Weese J., Blondeau J.M., Boothe D., Breitschwerdt E., Guardabassi L., Papich M.G., Rankin S., Turnidge J.D. \& Sykes J.E. 2014. Guidelines for the diagnosis and antimicrobial therapy of canine superficial bacterial folliculitis (Antimicrobial Guidelines Working Group of the International Society for Companion Animal Infectious Diseases). Veterinary Dermatology. 25(3): 163-e43.

9 Iwasaki T., Shimizu M., Obata H., Isaji M., Yanai T., Kitagawa H. \& Sasaki Y. 1997. Detection of canine pemphigus foliaceus autoantigen by immunoblotting. Veterinary Immunology and Immunopathology. 59(1-2): 1-10.

10 Larsson C.E. \& Lucas R. 2016. Tratado de Medicina Externa: Dermatologia Veterinária. São Caetano do Sul: Interbook, 853p.

11 Meyer D.J. \& Harvey J.W. 2004. Veterinary Laboratory Medicine: Interpretation \& Diagnosis. 2nd edn. Philadelphia: Saunders, 351p.

12 Naranjo C.A., Busto U., Sellers E.M., Sandor P., Ruiz I., Roberts E.A., Janecek E., Domecg C. \& Greenblatt D.J. 1981. A method for estimating the probability of adverse drug reactions. Clinical Pharmacology. 30(2): 239-245. 
13 Nayak S. \& Acharjya B. 2008. Adverse cutaneous drug reaction. Indian Journal of Dermatology. 53(1): 2-8.

14 Oberkirchner U., Linder K.E., Dunston S., Bizikova P. \& Olivry T. 2011. Metaflumizone-amitraz (Promeris)associated pustular acantholytic dermatitis in 22 dogs: Evidence suggests contact drug-triggered pemphigus foliaceus. Veterinary Dermatology. 22(5): 436-448.

15 Olivry T. 2006. A review of autoimmune skin diseases in domestic animals: I - superficial pemphigus. Veterinary Dermatology. 17(5): 291-305.

16 Park J.H., Kang J.H., Hyun J.E. \& Hwang C.Y. 2018. Low prevalence of Mupirocin resistance in Staphylococcus pseudointermedius isolates from canine pyoderma in Korea. Veterinary Dermatology. 29(2): 95-e37.

17 Ronet C., Passeli K., Charmoy M., Scarpellino L., Myburgh E., La Torre Y.H., Turco S., Mottram J.C., Fasel N., Luther S.A., Beverley S.M., Launois P. \& Tacchini-Cottier F. 2019. TLR2 Signaling in Skin Nonhematopoietic Cells Induces Early Neutrophil Recruitment in Response to Leishmania major Infection. Journal of Investigative Dermatology. 139(6): 1318-1328.

18 Ruocco V., Ruocco E., Lo Schiavo A., Brunetti G., Guerrera L.P. \& Wolf R. 2013. Pemphigus: Etiology, pathogenesis, and inducing or triggering factors: Facts and controversies. Clinical Dermatology. 31(4): 374-381.

19 Silva L.M. \& Roselino A.M.F. 2003. Reações de hipersensibilidade a drogas (farmacodermia). Revista Medicina. 36(2/4): 460-471.

20 Sung H.J., Yoon I.H. \& Kim J.H. 2017. Putative contact ketoconazole shampoo-triggered pemphigus foliaceus in a dog. The Canadian Veterinary Journal. 58(9): 914-918.

21 Tavakolpour S. 2018. Pemphigus trigger factors: special focus on pemphigus vulgaris and pemphigus foliaceus. Archives of Dermatological Research. 310(2): 95-106.

22 Visacri M.B., Souza C.M., Sato C.M.S., Granja S., Marialva M., Mazzola P.G. \& Moriel P. 2015. Adverse Drug Reactions and quality deviations monitored by spontaneous reports. Saudi Pharmaceutical Journal. 23(2): 130-137.

23 White S.D., Carlotti D.N., Pin D., Bonenberger T., Ihrke P.J., Monet E., Nishifuji K., Iwasaki T. \& Papich M.G. 2002. Putative drug-related pemphigus foliaceus in four dogs. Veterinary Dermatology. 13(4): 195-202.

24 Wolf R., Tamir A. \& Brenner S. 1991. Drug-induced versus drug-triggered pemphigus. Dermatologica. 182(4): 207-210. 